\title{
Renewable Energy to Support Energy Security
}

\section{Background}

Renewable energy plays an important role in supporting energy security through contributing to the protection and continued provision of energy services when a disruption occurs (DOE 2017). Sources of disruption to energy services can be natural, technological, and human-caused - such as weather events, cyberattacks, and global market disturbances.

Although energy systems have always been subject to disruption, potential threats are increasing in relation to reliance on energy for economic growth; intensifying weather events; and the growing potential of large-scale cyberattacks on increasingly networked energy systems. Such evolutions give urgency to understanding trends and vulnerabilities in emerging energy technologies, planning, and practices.

Institutions and governments around the world define energy security in different ways. The International Energy Agency (IEA) defines energy security as "the uninterrupted availability of energy sources at an affordable price." IEA also makes a distinction between long-term energy security for future economic development and short-term energy security that ensures energy systems will react quickly to sudden changes in the supply-demand balance (IEA). The
U.S. Department of State defines energy security as "access to diversified energy sources, routes, suppliers [in order to limit] the influence of a single dominant buyer, seller, or investor and guards against those who would use energy for coercive ends" (DOE 2017).

Energy security is vital to many sectors of the economy. Examples include, but are not limited to, the following:

Industry: Nearly all modern industries depend on reliable and affordable power supplies. Power outages and poor power quality can cause damage to manufacturing equipment and impact production. Unstable energy prices can impact the economics of producing goods and services.

Food: The globalized industrial food system is largely dependent on fossil fuels to power farming equipment, produce pesticides and fertilizer, and transport goods. To prevent food from spoiling, reliable power is needed to keep produce cool in refrigerated warehouses or transportation containers. Rising fuel and energy prices can impact food prices and affordability (Neff, Parker, Kirschenmann, Tinch, and Lawrence 2011).

Health Care: Interruptions to power supplies can impact medical centers and hospitals. Certain treatments or medical care protocols rely on dependable power (e.g., dialysis centers and operating rooms). Vulnerable patients can die from heat or cold exposure. The blackouts in Puerto Rico after Hurricanes Maria and Irma in 2017 greatly impacted the chronically ill who relied on electricity to power health care machines. Deaths due to chronic illness after the hurricanes surged in comparison to the same period in 2016 (Hernandez, Learning., and Murphy 2017).

Other Critical Services: Power is also essential in providing other critical services related to water and sanitation and telecommunications, among others. Provision of these services is especially critical in the aftermath of a disaster to avoid cascading negative impacts and enable recovery.

\section{Threats to Energy Security}

Threats to the energy sector can be natural, technological, or humancaused-and can damage, destroy, or disrupt energy systems (Resilient Energy Platform). A community that is energy-secure will incorporate resilient systems and approaches that can prevent, mitigate, or allow for adaptation to threats and changing conditions. Examples of threats to the energy sector include:

$1 \mathrm{It}$ is important to note that energy security is not the same as energy sovereignty. Energy sovereignty refers to the ability of a community or nation to internally produce all necessary energy; however, energy sovereignty does not mean a community is energy secure. As an example, a jurisdiction that internally produces $100 \%$ of its energy from solar power may not be energy secure if they experience natural disasters that threaten solar photovoltaic (PV) systems. 
Natural Disasters: Severe weather events like droughts and storms are projected to become more intense and destructive (IPCC 2012). These events can decrease or disrupt supplies and negatively impact energy infrastructure (Rudnick 2011). In the United States, severe weather is the number one cause of power outages (Executive Office of the President 2013).

Cyberattacks: The energy sector is becoming more automated, digitized, and interconnected. Cyberattacks are becoming more common and could pose a greater threat as the energy sector becomes more modern and connected (IEA).

Geopolitics: Interstate conflicts can threaten energy security. For example, the 1973 oil crisis resulted from an embargo by the Organization of Petroleum Exporting Countries on the United States (U.S. Department of State). Political instability in fuel producing nations can impact energy prices.

\section{Fuel Price Fluctuations: Changes} in fuel prices (e.g., related to market or other factors) can threaten energy security through impacting a nation's or community's ability to purchase fuels.

\section{Long-Term Climatic Changes:}

Changing environmental conditions like air temperature, water temperature, and water availability can cause stress to energy systems.

- Rising temperatures increase the demand for air conditioning, most significantly impacting summer peak energy demands (Zamuda, Bilello, Conzelmann, Mecray, et al. 2018).

- Water is necessary for energy production. Hydroelectric systems depend on flow, and some electricity production systems need water for

\section{The Connection Across Energy Security and Resilience}

Energy security and resilience are related and, in many cases, interlinked. Countries and jurisdictions think about the relationship between energy security and resilience in different ways. For example, the Government of Laos recently undertook a power sector vulnerability assessment that fed into a resilience action plan. This plan is seen as supporting a broader country objective to enable energy security. In most cases, energy security is seen as an overarching objective, and resilience is seen as an energy system characteristic that can contribute to energy security through enabling adaptation to changing conditions and recovery from disruptions. Figure 1 presents one perspective for considering the interlinkage across energy security and energy resilience.

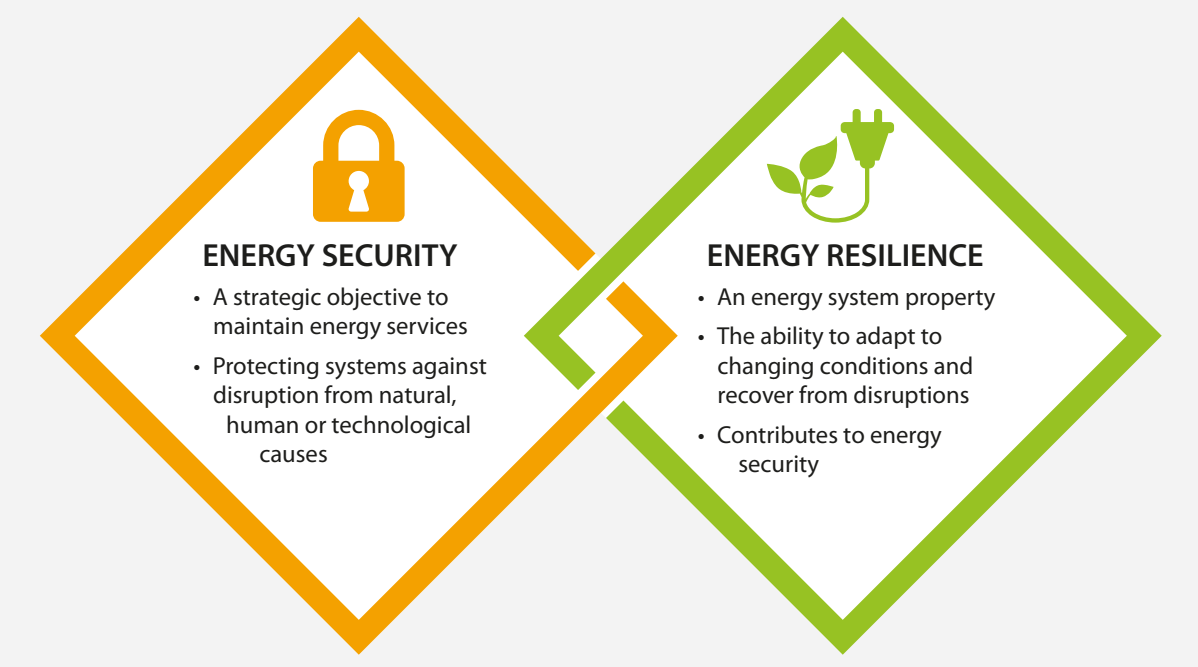

Figure 1. Interlinkage of Energy Security and Energy Resilience.

Illustration by Brittany Conrad, NREL

cooling. Reduced precipitation or increased water temperatures can impact supply by limiting power plant capacity. Snowpack melt changes (i.e., the timing of melt and runoff in the spring or summer) changes peak production for hydroelectric systems (Zamuda, Bilello, Conzelmann, Mecray, et al. 2018).

- Changes in sea levels or storm surges can impact energy infrastructure close to shorelines, due to flooding (EPA).

\section{How Can Renewable Energy Support Energy Security?}

Energy security remains a key objective of many countries around the world.
Deploying renewable energy technologies supports the goal of energy security and supports the realization of additional benefits.

\section{Diversifying the Generation Mix:}

Renewable energy can support energy security by adding diversity to an overall electricity generation portfolio. Diversity of a power generation portfolio can relate to the spatial location, types of generation resources, and fuel sources or supply.

- Spatial diversity-A more spatially diverse generation and storage energy portfolio can better withstand shocks to the system. With more resources across different geographic 
areas, such diversity could power infrastructure during disasters, cyberattacks, or other extreme events. Spatially diverse energy generation portfolios can also provide a smoothing effect across variable generation resources, allowing for improved reliability and integration of variable renewables (Cox, Hotchkiss, Bilello, Watson, et al. 2017).

\section{What is a Power System Threat?}

Anything that can damage, destroy, or disrupt the power system is considered a threat. Threats can be natural, technological, or caused by human activity. Threats are not typically within the control of the power system planners and operators and can include wildfires, cyclones or typhoons, droughts, longer term temperature changes, cyberattacks, and many others.

Learn more at: https://resilientenergy.org/guidebook

- Resource and fuel diversity — Having a majority reliance on one specific fuel type makes the power system vulnerable to fuel supply constraints or price fluctuations. Diversifying energy portfolios with renewable energy can help communities reduce dependence on fuel imports, especially in island nation settings. Further, renewable electricity prices are often stable, in contrast to regularly shifting fossil fuel prices due to geopolitical, market, or other factors (Olz, Sims, and Kirchner 2007).
Reducing Water Use: Technologies with high water requirements are vulnerable to drought or other climatic events. Deploying renewable energy can reduce potential fluctuations or uncertainty in power generation portfolios that depend on hydro or require significant amounts of water for generation or cooling.

\section{Modularity and Rapid Deployment:}

According to Cox et al. "Modularity [of distributed renewable technologies] allows for locational flexibility and for new generation systems to be put in place at a faster pace than large-scale systems as electricity demand grows and understanding of climate risks improves." Modularity can support energy security through rapid deployment of more modular, distributed energy systems in response to changing threats. In addition, modularity can support the diversification of energy generation, as distributed systems have greater locational flexibility and can be deployed in diverse settings. Finally, when a part of a modular system is damaged or fails it is typically easier to repair than a larger system failure. In some cases, the section that is damaged can be removed while the rest of the system continues to function, or the part replacement can occur quickly.

Islanding: Renewable distributed generation technologies can be equipped with control mechanisms to support "islanding" of on-site power sources in the event of a disaster. Islanding controls can isolate a distributed power source from other systems, allowing them to continue to provide power locally even if the main grid is compromised or disrupted. Importantly, islanded distributed energy systems (especially when combined with storage) can provide power to critical facilities, such as hospitals, water treatment facilities, or vulnerable communities, in a safe manner.

Coupling with Storage: A renewable based energy system, utility-scale or distributed, can further support energy security when coupled with energy storage technologies. Storage allows for fluctuations of a generation technology (e.g., solar PV or wind), while providing power to a site through stored power (e.g., a charged battery system). In addition, storage can provide backup power in the event of an outage and potentially allow for black start recovery $^{2}$ when the system is designed to do so. In alignment with energy security objectives, energy storage can also support stabilization of electricity prices, management of demand changes, and mitigation of curtailment.

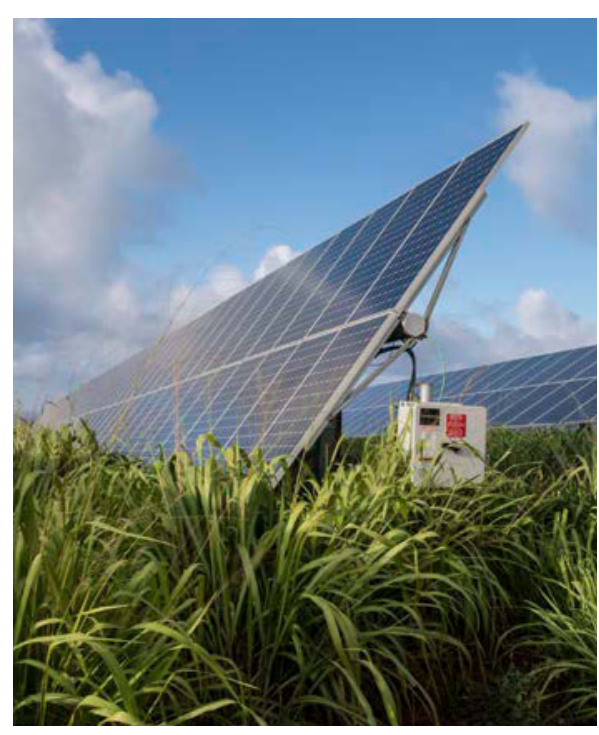

Deploying renewable energy technologies supports the goal of energy security and supports the realization of additional benefits. Photo by Dennis Schroeder, NREL 58004

\section{Resilient Energy Platform}

The Resilient Energy Platform helps countries to address power system vulnerabilities by providing strategic resources and direct country support, enabling planning and deployment of

2 "Black Start is the procedure [used] to restore power in the event of a total or partial shutdown of [a] national electricity transmission system" (National Grid ESO). 
resilient energy solutions. This includes expertly curated reference materials, training materials, data, tools, and direct technical assistance in planning resilient, sustainable, and secure power systems. Ultimately, these resources enable decision makers to assess power sector vulnerabilities, identify resilience solutions, and make informed decisions to enhance energy sector resilience at all scales (including local, regional, and national scales). To learn more about the solutions highlighted in this fact sheet, please visit the Platform at: resilient-energy.org.

\section{Additional Resources}

ADB (Asian Development Bank). Climate Risk and Adaptation in the Electric Power Sector. Manila, Philippines: Asian Development Bank. July 2012. https:// www.adb.org/publications/climate-riskand-adaptation-electric-power-sector.

Baldwin, David A. "The Concept of Security." Review of International Studies 23, no. 1 (January 1997): 5-26. https:// doi.org/10.1017/S0260210597000053.

Cox, Sadie, Pieter Gagnon, Sherry Stout, Owen Zinaman, Andrea Watson, and Eliza Hotchkiss. Distributed Generation to Support Development-Focused Climate Action. NREL/TP-6A20-66597. September 2016. https://www.nrel.gov/ docs/fy16osti/66597.pdf.

Cronin, Jennifer, Gabrial Anandarajah, and Olivier Dessens. "Climate Change Impacts on the Energy System: A Review of Trends and Gaps." Climatic Change 151, no. 2 (August 2018): 79-93. https://doi.org/10.1007/ s10584-018-2265-4.

DOE (U.S. Department of Energy). "U.S. Energy Sector Vulnerabilities to Climate Change and Extreme Weather." Washington, D.C.: DOE. July 2013. https://www.energy.gov/downloads/ us-energy-sector-vulnerabilities-climate-change-and-extreme-weather.
Ebinger, Jane, and Walter Vergara. Climate Impacts on Energy Systems: Key Issues for Energy Sector Adaptation. 60051. Washington, D.C.: The World Bank. March 2010. http:// documents.worldbank.org/curated/ en/580481468331850839/Climateimpacts-on-energy-systems-key-issuesfor-energy-sector-adaptation.

Hache, Emmanuel. "Do Renewable Energies Improve Energy Security in the Long Run?" International Economics 156 (December 2018): 127-35. https://doi. org/10.1016/j.inteco.2018.01.005.

Hotchkiss, Eliza, Alex Dane, and Connie Komomua. "Resilience Roadmap." Golden, CO: NREL. 2018. https://www. nrel.gov/resilience-planning-roadmap/.

Hughes, Larry. "The Four'R's of Energy Security." Energy Policy 37, no. 6 (June 2009): 2459-61. https://doi. org/10.1016/j.enpol.2009.02.038.

Mission Support Center, Idaho National Laboratory. Cyber Threat and Vulnerability Analysis of the U.S. Electric Sector. August 2016. https://www. energy.gov/sites/prod/files/2017/01/ f34/Cyber\%20Threat\%20and\%20 Vulnerability\%20Analysis\%20of\%20 the\%20U.S.\%20Electric\%20Sector.pdf.

Stout, Sherry, Nathan Lee, Sadie Cox, James Elsworth, and Jennifier Leisch. Power Sector Resilience Planning Guidebook. NREL/TP-7A40-73489. June 2019. https://resilient-energy.org/ guidebook.

UNDP (United Nations Development Programme). Mapping Climate Change Vulnerability and Impact Scenarios. November 2010. https://www.undp. org/content/undp/en/home/librarypage/environment-energy/low_emission_climateresilientdevelopment/ mapping-climate-change-vulnerability. html.
USAID (United States Agency for International Development). Climate Vulnerability Assessment. https://www. climatelinks.org/resources/climate-vulnerability-assessment-annex-usaid-climate-resilient-development-framework

World Bank Group. Enhancing Power Sector Resilience: Emerging Practices to Manage Weather and Geological Risks. June 2016. https://openknowledge. worldbank.org/handle/10986/26382.

World Business Council for Sustainable Development. Building a Resilient Power Sector. Geneva: WBCSD. 2014. http://www.wbcsd.org/ Clusters/ClimateEnergy/Resources/ Building-a-ResilientPower-Sector.

Wilson, R. and B. Biewald. 2013."Best Practices in Electric Utility Integrated Resource Planning." Synapse Energy Economics, Inc. http://www.raponline. org/wp-content/uploads/2016/05/ rapsynapsewilsonbiewald-bestpracticesinirp-2013- jun-21.pdf. World Future Council. 2016."Renewable Energy and Sustainable Development. Accounting for Impacts on the Path to 100\% RE." https://www.worldfuturecouncil.org/ file/2016/08/WFC_2016_RenewableEnergyand-Sustainable-Development.pdf.

\section{References}

Cox, Sadie, Eliza Hotchkiss, Dan Bilello, Andrea Watson, Alison Holm, and Jennifer Leisch. Bridging Climate Change Resilience and Mitigation in the Electricity Sector Through Renewable Energy and Energy Efficiency. NREL/TP-6A20-67040. November 2017. https://www.iea.org/ publications/freepublications/publication/so_contribution.pdf.

DOE (U.S. Department of Energy). Valuation of Energy Security for the United States. Washington, D.C.: DOE. January 2017. https://www.energy.gov/sites/ prod/files/2017/01/f34/Valuation\%20 of\%20Energy $\% 20$ Security $\% 20$ 
for\%20the $\% 20$ United $\% 20$ States $\% 20$

\%28Full\%20Report\%29_1.pdf.

EPA (Environmental Protection Agency).

"Climate Impacts on Energy." https://

19january2017snapshot.epa.gov/

climate-impacts/climate-impacts-

energy_html.

Executive Office of the President.

Economic Benefits of Increasing Electric

Grid Resilience to Weather Outages.

August 2013. https://www.energy.gov/

sites/prod/files/2013/08/f2/Grid\%20

Resiliency\%20Report_FINAL.pdf.

Hernandez, Arelis, Whitney Learning, and Zoeann Murphy. "Sin Luz: Life

Without Power." Washington Post.

December 14, 2017. https://www. washingtonpost.com graphics/2017/ nationalpuerto-rico-life-without-power/.

IEA (International Energy Agency).

"Resilience." Accessed July 9, 2019.

https://www.iea.org/topics/

energysecurity/resilience/.

IEA. "What is energy security?"

Accessed July 10, 2019. https://

www.iea.org/topics/energysecurity/

whatisenergysecurity/.

IPCC (Intergovernmental Panel on

Climate Change). Managing the Risks of
Extreme Events and Disasters to Advance Climate Change Adaptation. A Special Report of Working Groups I and II of the Intergovernmental Panel on Climate Change. Cambridge University Press, Cambridge, United Kingdom. 2012. https://wg1.ipcc.ch/srex/downloads/ SREX-All_FINAL.pdf.

National Grid ESO. "Black Start." https:// www.nationalgrideso.com/balancingservices/system-security-services/

black-start.

Neff, Roni, Cindy Parker, Frederick Kirschenmann, Jennifer Tinch, and Robert Lawrence. "Peak Oil, Food Systems, and Public Health." American Journal of Public Health 101, no. 9 (September 2011): 1587-1597. 10.2105/ AJPH.2011.300123.

Olz, Samantha, Ralph Sims, and Nicolai Kirchner. Contribution of Renewables to Energy Security. April 2007. https:// www.iea.org/publications/freepublications/publication/so_contribution.pdf.

Resilient Energy Platform. "Glossary."

Accessed July 10, 2019. https://

resilient-energy.org/about/glossary.

Rudnick, Hugh. "Impact of Natural

Disasters on Electricity Supply." IEEE

Power and Energy Magazine 9, no. 2 (May 2011): 22-26. https://www.researchgate.
net/publication/224221616_Impact_ of_Natural_Disasters_on_Electricity_ Supply_Guest_Editorial.

U.S. Department of State. "Oil Embargo, 1973-1974." Office of the Historian, Foreign Service Institute. Accessed July 9, 2019. https://history.state.gov/ milestones/1969-1976/oil-embargo.

Zamuda, C., D.E. Bilello, G. Conzelmann, E. Mecray, A. Satsangi, V. Tidwell, and B.J. Walker, 2018: Energy Supply, Delivery, and Demand. In Impacts, Risks, and Adaptation in the United States: Fourth National Climate Assessment, Volume II [Reidmiller, D.R., C.W. Avery, D.R. Easterling, K.E. Kunkel, K.L.M. Lewis, T.K. Maycock, and B.C. Stewart (eds.)]. U.S. Global Change Research Program, Washington, DC, USA, pp. 174-201. doi: 10.7930/NCA4.2018.CH4

\section{www.resilient-energy.org | www.nrel.gov/usaid-partnership}

Jennifer E. Leisch, Ph.D.

USAID-NREL Partnership Manager

U.S. Agency for International Development Tel: +1-303-913-0103 | Email: jleisch@usaid.gov

\section{Sadie Cox}

Senior Researcher

National Renewable Energy Laboratory

Tel: +1-303-384-7391 | Email: sadie.cox@nrel.gov

This work was authored, in part, by the National Renewable Energy Laboratory (NREL), operated by Alliance for Sustainable Energy, LLC, for the U.S. Department of Energy (DOE) under Contract No. DE-AC36-08GO28308. Funding provided by the United States Agency for International Development (USAID) United States Agency for under Contract No. IAG-17-2050. The views expressed in this
report do not necessarily represent the views of the DOE or the report do not necessarily represent the views of the DOE or the
U.S. Government, or any agency thereof, including USAID.

NREL/TP-6A20-74617 | October 2019

NREL prints on paper that contains recycled content.
The Resilient Energy Platform provides expertly curated resources, training, tools, and technical assistance to enhance power sector resilience. The Resilient Energy Platform is supported by the U.S. Agency for International Development.

The USAID-NREL Partnership addresses critical challenges to scaling up advanced energy systems through global tools and technical assistance, including the Renewable Energy Data Explorer, Greening the Grid, the International Jobs and Economic Development Impacts tool, and the Resilient Energy Platform. More information can be found at: www.nrel.gov/usaid-partnership.

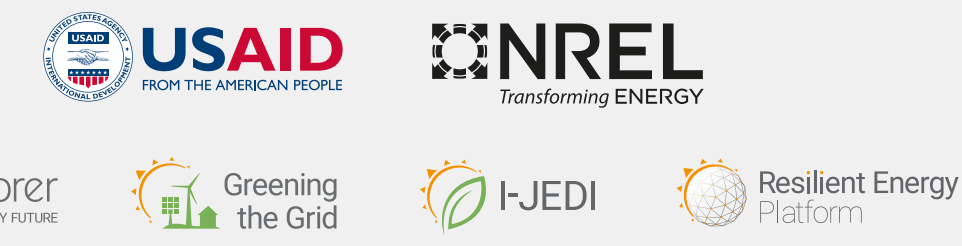

